\title{
Correspondence
}

\section{Amyloid arthropathy in patients with chronic renal failure}

SIR, Doctor Freemont suggests that the articular amyloid deposits in haemodialysed patients could simply represent an epiphenomenon without clinical significance. ${ }^{1} \mathrm{He}$ compares these deposits with those noted in osteoarthritis, and indeed such occurrence has been recently re-emphasised. ${ }^{2}$ We have had the opportunity, however, to observe several cases of histologically proved haemodialysis amyloid arthropathy, ${ }^{3}$ some of which have been published, including radiographs and histological data. ${ }^{+6}$ It is apparent that in most patients on long term haemodialysis these amyloid deposits are identical both clinically and radiologically with amyloid arthropathies observed in multiple myeloma, ${ }^{7}$ for example, articular bone erosions and bone fractures at the level of capsular attachments may appear in the course of the disease. The pain and stiffness of the affected joints. mostly the wrists, shoulders, and hips, are often severe and become progressively worse. Digital flexor tendon sheaths may become swollen and painful causing inability to extend the fingers, and a severe carpal tunnel syndrome may ensue. Moreover, we observed two cases of erosions on the posterior aspect of the spine in the vicinity of the facet joints (Fig. 1). All these data argue against the suggestion that the haemodialysis amyloid articular deposits are a simple epiphenomenon. Furthermore, severe systemic amyloidosis has been described in long term haemodialysed patients, suggesting that it may evolve into a severe and fatal disease in these patients. ${ }^{48}$

Rheumatology Unit, Department of Medicine, C NAGANT DE DEUxChAISNES St-Luc University Hospital.

Louvain University in Brussels,

B-1200 Brussels.

Belgium

\section{References}

1 Freemont A J. Amyloid arthropathy in patients with chronic renal failure. Ann Rheum Dis 1986; 45: 349.

2 Mitrovic D R. Stankovic A. Quintero M. Ryckewaert A. Amyloid deposits in human knee and hip joints. Rheumatol Int $\mathrm{O}$ 1985: 5: 83-9.

3 Vandenbroucke J M. Huaux J P. Nagant de Deuxchaisnes C. van Ypersele de Strihou C. Dialysis arthropathy: complication $\stackrel{9}{\mathcal{O}}$ of long term treatment with hacmodialysis. Br Med J 1986: 292: 응 556 .

4 Huaux J P. Noël H. Bastien P. et al. Amylose articulaire. fracture du col fémoral et hémodialyse périodique chroniqug Rev. Rhum Mal Osteoartic 1985: 52: 179-82.

5 Huaux J P. Noël H. Malghem J. et al. Amyloidosis. a possił contributing factor to bone erosions and cysts in azotemic re? osteodystrophy on long term hemodialysis. In: Norman A Schaefer K. Grigoleit H G. v Herrath D, eds. Biochemical and clinical update. Berlin: Walter de Gruyter. 1985: 1137-8.

6 Huaux J P. Noël H. Malghem J. Maldague B. Devogelaer J P. Nagant de Deuxchaisnes C. Erosive azotemic osteoarthropathy: ¿ possible role of amyloidosis. Arthritis Rheum 1985: 28: 1075-6. F

7 Kavanaugh J H. Multiple myeloma, amyloid arthropathy, and

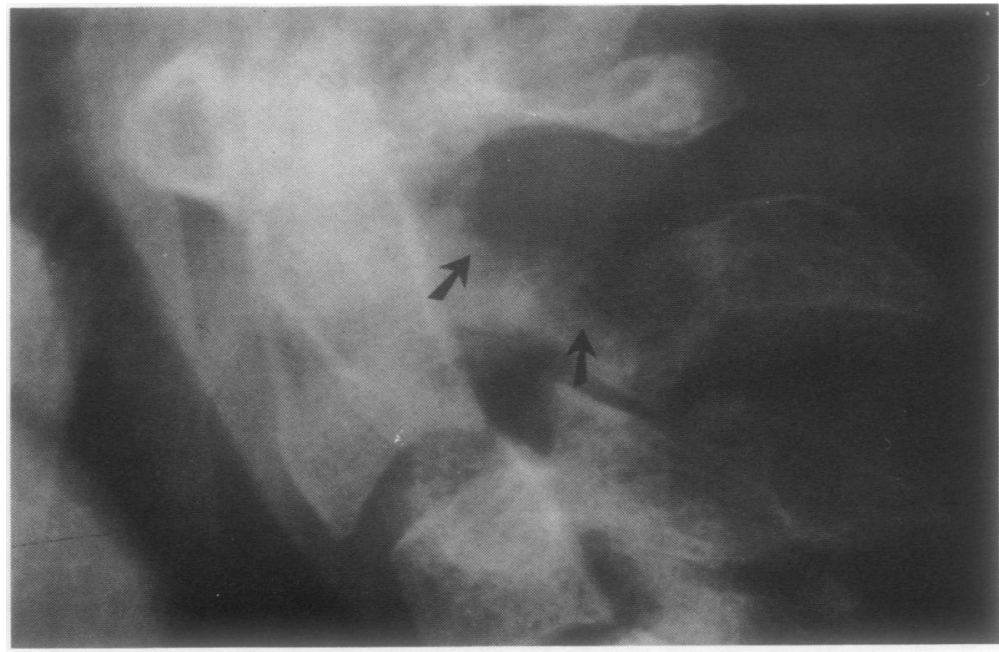

Fig. 1 Lateral view of the cervical spine in a patient on haemodialysis for a 16 year period. He suffered from a severe arthropathy of shoulders, wrists, and hips with femoral neck fractures. ${ }^{6}$ There is a large defect (arrows) of the posterior aspect of the spine at the level $\mathrm{Cl}-2$ related to amyloidosis. 
pathological fracture of the femur. A case report. J Bone Joint Surg [Am] 1978; 60: 135-7.

8 Hervé J P, Cledes J, Bourbigot B, et al. Apparition d'une amylose généralisée au cours de l'hémodialyse: à propos d'une observation. Nephrologie 1984; 5: 92.

SIR, Further to Dr Huaux's letter I would like to make it clear that I do not challenge in any way the observations made by his and other groups, nor do I reject the concept of amyloid induced bone and joint disease in patients receiving chronic haemodialysis. My criticism is of the interpretation of the results. The discovery of amyloid in symptomatic joints of patients undergoing haemodialysis is not of itself evidence that it is responsible for the symptoms. Only after adequate control studies have failed to show the presence of amyloid in asymptomatic but otherwise adequately matched patients should a possible pathogenetic link between amyloid and the connective tissue disorders associated with haemodialysis be postulated. It is perhaps worth summarising the evidence for 'amyloid arthropathy' and discussing its potential significance.

There is a syndrome manifested most frequently by joint pain or carpal tunnel syndrome, or both, which is a significant cause of morbidity in patients undergoing long term haemodialysis. It affects as many as $30 \%$ of patients on dialysis for more than seven years, ${ }^{1}$ and some of its clinical and radiological manifestations are reminiscent of the amyloid deposition disease seen in other disorders. Amyloid is present in many symptomatic sites in this syndrome but is also recognised to occur in association with carpal tunnel syndrome in non-dialysed patients ${ }^{2}$ and in the joints of asymptomatic dialysis patients. The amyloid in dialysis patients contains the protein $\beta_{2}$ microglobulin $\left(\beta_{2} M\right),{ }^{3}$ increased serum levels of which are found in patients with renal failure, including patients undergoing haemodialysis and those receiving continuous ambulatory peritoneal dialysis. ${ }^{4}$ Only in haemodialysis patients dialysed across conventional cellulose type membranes is the syndrome encountered.

If $\beta_{2} \mathrm{M}$ amyloid is the cause of the syndrome then removing it or preventing its accumulation should be the therapeutic goal. $\beta_{2} \mathrm{M}$ can be removed at dialysis if a highly permeable dialysis membrane material such as polyacrylonitrile is used instead of the conventional cellulose. ${ }^{5}$ The long term use of this membrane may well reduce the incidence of 'amyloid arthropathy'.

There is, therefore, circumstantial evidence causally implicating $\beta_{2} \mathrm{M}$ amyloid in this syndrome. If all the disparate studies connect in the ways suggested then the logical therapeutic response would be to change all dialysis membranes. This has a variety of far reaching implications, and any decision needs to be based on sound scientific evidence. In particular, it is mandatory that the basic premise-amyloid causes the symptoms-is correct. It may well be, but I am still not convinced that the uncontrolled studies performed to date are adequate proof of this connection. Adequate control studies would be simple to undertake, and until it can be shown that amyloid is not a universal finding in the joints of patients receiving long term haemodialysis treatment, use of the term 'amyloid arthropathy' with all its attendant pathogenetic implications cannot be justified.

Department of Rheumatology,

A J FREEMONT

Stopford Building,

Oxford Road,

Manchester M13 9PT

\section{References}

1 Vandenbroucke J M, Jadoul M, Maldague B, Huaux J P, Noel H, van Ypersele de Strihou C. Possible role of dialysis membrane characteristics in amyloid osteoarthropathy. Lancet 1986; i: $1210-1$.

2 Walts A E, Goodman M D, Matcrin P A. Amyloid, carpal tunnel syndrome and chronic hemodialysis. Am J Nephrol 1985; 5: 225-6.

3 Gejyo F, Yamada T, Odani S. A new form of amyloid protein associated with chronic haemodialysis was identified as $\beta_{2}$ microglobulin. Biochem Biophys Res Commun 1985; 129: 701-6.

4 Ballardie F W, Kerr D N S, Tennent G. Pepys M B. Haemodialysis versus CAPD: equal predisposition to amyloidosis? Lancet 1986; i: 795-6.

5 Hauglustaine D. Waer M. Michielsen P. Goebels J. Vandeputte $M$. Haemodialysis membranes, serum $\beta_{2}$ microglobulin and dialysis amyloidosis. Lancet 1986; i: 1211.

\section{Amyloid arthropathy in haemo- dialysed patients}

SIR, Two recent letters to the editor in the Annals ${ }^{2}$ about our paper on amyloid arthropathy in patients undergoing haemodialysis ${ }^{3}$ have suggested that the finding of amyloid in the synovial tissue or fluid, or both, of these patients could be interpreted as an epiphenomenon related mainly to aging and osteoarthritis.

We would like to point out the following facts. The patients presented a rather characteristic picture (persistent swelling of several joints. mainly shoulders, knees, wrists, finger tenosynovitis, and carpal tunnel syndrome). Their $x$ rays did not show osteoarthrosis but geodes and erosions that can lead to a destructive arthropathy, and as has been reported by other authors ${ }^{45}$ it is possible to demonstrate amyloid in the bone as well as in the synovial tissue. In a study that we have just finished we failed to show amyloid in synovial tissue and synovial fluid in 10 age matched patients with diverse rheumatic diseases.

These facts make it improbable that aging and osteoarthrosis were the cause of the amyloid deposition in our cases, beside the fact that in these other circumstances the synovial deposits are minimal and, as far as I know, of little clinical significance.

The tinctorial characteristics of the amyloid, using the Wright technique, in our cases pointed towards an amyloid of immunological origin ( $\mathrm{AL}$ amyloid). Recently the biochemical nature of amyloid in amyloidosis associated with haemodialysis has been identified as a protein homologous with normal plasmatic $\beta_{2}$ microglobulin, which is known to accumulate in the circulation of patients with chronic renal failure and because of its size cannot be removed from the plasma during haemodialysis.

We have started immunohistochemical analysis of the amyloid found in our patients, and at this stage we have 